\title{
TST RECONHECE COMPETÊNCIA DIFERENCIADA SOBRE MEIO AMBIENTE
} DO TRABALHO

\author{
Beatriz Souza Costa ${ }^{1}$ \\ Thiago Loures Machado Moura Monteiro
}

\section{RESUMO}

Este artigo trata do reconhecimento pelo TST, de uma competência diferenciada para ações envolvendo meio ambiente do trabalho, mesmo em causas que envolvam servidores estatutários. A metodologia aplicada é a interpretação da norma, por uma lógica dedutiva. Para tanto será promovida a pesquisa bibliográfica qualitativa com análise de jurisprudência, sendo abordados também posicionamentos divergentes, e a evolução jurisprudencial do TST. Como marco teórico do presente artigo, é tido o julgado do processo de $\mathrm{n}^{\circ} 128500$ 70.2013.5.13.0025, pelo TST. Os resultados apontam que é necessária uma tutela processual diferenciada, desde as normas de competência, pela natureza o direito tutelado.

Palavras-chave: Direito Processual; Competência; Meio ambiente do trabalho; Tutela Diferenciada; Evolução Jurisprudencial.

\section{TST RECOGNIZES DIFFERENTIATED COMPETENCE ON THE WORKING ENVIRONMENT}

\begin{abstract}
This article deals with the recognition by the TST, of a differentiated competence for actions involving the working environment, even in causes which involves statutory servers. The methodology applied is the interpretation of standard, by a deductive logic. For this purpose, the bibliographic research with qualitative analysis of jurisprudence will be promoted, also addressing divergent positions, and the jurisprudential development of the TST. As theoretical framework of this article, is considered the judgment of the process $n^{\circ} 128500$ 70.2013.5.13.0025, by the TST. The results indicate that it is necessary a differentiated procedural tutelage, since the rules of jurisdiction, by the protected right.
\end{abstract}

Keywords: Procedural Law; Competence; Working Environment; Differentiated Tutelage; Jurisprudential Development.

\section{INTRODUÇÃO}

\footnotetext{
${ }^{1}$ Doutora e Mestre em Direito Constitucional pela Faculdade de Direito da Universidade Federal de Minas Gerais - UFMG. Docente do Programa de Mestrado da Escola Superior Dom Helder Câmara.

${ }^{2}$ Mestre em Direito Ambiental na Escola Superior Dom Helder Câmara, Pós-graduado em Direito do Trabalho na Universidade FUMEC. Professor de Direito do Trabalho na Escola Superior Dom Helder Câmara.
} 
O tempo médio para duração da tramitação de um processo costuma ser menor na Justiça do Trabalho, do que na Justiça Comum, fator proporcionado por vários fatores como ser uma Justiça Especializada, que atende apenas determinado ramo do Direito.

No dia 18.08.2015, foi publicado precedente no Tribunal Superior do Trabalho, julgado pela $1^{\text {a }}$ Turma, nos autos de $n^{\text {o: }}$ 128500-70.2013.5.13.0025, acerca da competência da Justiça do Trabalho, para processar e julgar ação civil pública que envolva meio ambiente do trabalho, em prol da tutela de condições de trabalho tanto de trabalhadores celetistas, quanto de servidores estatutários, sendo que sua análise corresponde ao tema central da presente artigo.

Assim, o problema central proposto, consiste em verificar se é possível que a Justiça do Trabalho seja competente para julgar ações sobre o meio ambiente do trabalho de servidores estatutários, que em regra, têm de discutir seus direitos sociais na Justiça Comum, sendo o julgado acima citado, o referencial teórico da pesquisa.

Antes de adentrar nas discussões, controvérsias, e possíveis desdobramentos do referido julgado, é essencial conceituar certos institutos, como o meio ambiente, o meio ambiente do trabalho, e ainda a ação civil pública ambiental.

Desse modo a pesquisa tem como objetivo central analisar as peculiaridades da tutela ambiental na regra de competência da Justiça do Trabalho, e como objetivos específicos destacam-se: compreender o conceito de meio ambiente do trabalho; expor os princípios aplicáveis ao caso; analisar a evolução jurisprudencial sobre o tema competência para meio ambiente do trabalho.

Ato seguinte será abordado o primeiro aspecto, e talvez o mais paradigmático do julgado, qual seja, a cerca dos limites da competência da justiça do trabalho, em se tratando de servidores públicos estatutários, envolvendo meio ambiente do trabalho.

Para tanto, erá adotada a metodologia da interpretação da norma, por uma lógica dedutiva. Adotando técnica de pesquisa qualitativa com análise de jurisprudência. Realizando um estudo evolutivo jurisprudencial, considerando as alterações da emenda constitucional 45/2004 no art. 114 da Constituição Federal, e os efeitos da liminar na ADI 3395, bem como a inteligência da súmula 736 do STF, em razão da tutela diferenciada em matéria de direito ambiental, pelo comando do art. 225 da Constituição.

Em sequência, adentrando-se ao mérito do julgado em questão, será discutido sobre a possibilidade de se superar o argumento de separação de poderes, considerando o caráter 
transgeracional da tutela ambiental, em uma análise principiológica, decorrente da teoria de Dworkin para aplicação de princípios constitucionais.

Por derradeiro, o artigo trará como conclusão, possíveis desdobramentos do julgado estudado, não apenas no âmbito jus laboral, mas sim no ordenamento jurídico como um todo, ressaltando necessidade em se garantir a tutela ambiental, como forma reflexa de se garantir o direito a vida. Sendo que a importância do tema tratado se justifica, pois apresenta uma exceção para os servidores estatutários pleitearem tutela da Justiça do Trabalho, se o direito em questão for sobre meio ambiente do trabalho.

\title{
2 O MEIO AMBIENTE DO TRABALHO
}

Prima face, importante definir um conceito de meio ambiente, pois fato é que o meio ambiente do trabalho, por evidente é um desdobramento do primeiro, que precisa ser definido, ainda que de forma ampla, para viabilizar seu manejo mais adequado.

O conceito legal previsto no artigo $3^{\circ}$ da lei de Política Nacional do Meio Ambiente ${ }^{3}$, não é o mais apropriado, até mesmo por ser um conceito criado antes do advento da Constituição Federal de 1988, que trouxe um novo patamar de direito fundamental, ao direito ambiental.

Sobre a necessária amplitude no conceito de meio ambiente já com um enfoque da Constituição de 1988, assim dispõe Paulo Jose Leite Farias:

\begin{abstract}
Ao tratar-se das normas ambientais trazidas na Constituição, mister se faz verificar a interpretação das normas sob o paradigma ambiental, analisar o peso dos princípios e a questão e a questão dos interesses e suas colidências, para então, verificar as normas positivadas no texto constitucional. Observa-se que tal atitude se mostra imprescindível, pois, conforme o amplo conceito adotado nesta obra, o meio ambiente deve ser visto sob o ponto de vista sistêmico, o que ocasiona sua interação com todo o ordenamento jurídico. (FARIAS, 1999, p. 223)
\end{abstract}

Nota-se que o Paulo Jose Leite Farias, trabalha com a teoria de Alexy, sobre ponderação de princípios, considerando o critério de sopesamento a partir das colisões de princípios, teoria da qual o presente artigo não coadunará, como será explicado mais adiante.

\footnotetext{
${ }^{3}$ O conceito legal de meio ambiente pela Lei 6.938/81 é: "meio ambiente, o conjunto de condições, leis, influências e interações de ordem física, química e biológica, que permite, abriga e rege a vida em todas as suas formas".
} 
Mas como posicionamentos diversos enriquecem a construção do Direito, fica registrado o posicionamento do renomado autor. Destacando que mesmo partindo por outra teoria, se conclui ser importante, definir um conceito amplo para meio ambiente, a luz da Constituição de 1988.

Assim, será adotado o conceito de meio ambiente, com lentes constitucionais, considerando ainda o dever de harmonia e solidariedade, para concretização do comando do caput do artigo 225 da Constituição:

Após muita leitura e análise sobre o conceito de meio ambiente, este é o conceito para este trabalho: Meio ambiente é o conjunto de elementos naturais e artificiais partilhados com seres humanos e não humanos, necessários ao desenvolvimento e sobrevivência dessas espécies de forma harmônica e solidária. (COSTA, 2016, p. 73)

Após a conceituação de meio ambiente, é possível concluir que o instituto está presente no dia a dia laboral do ser humano, por ter partilhado com o trabalhador, um conjunto de elementos naturais e artificiais, que afetam direta e indiretamente sua vida sadia, com Dignidade, que inclusive fundamento da república previsto no artigo $1^{\circ}$ da Carta Magna de 1988.

Nesse aspecto, quando se fala em direito à participação popular em questões sobre meio ambiente do trabalho, para verificar a legitimidade do cidadão, basta verificar se o mesmo foi afetado:

The main objective of the public participation is to insure the exercise of citizenship and democracy in the environmental impact assessment process, a time when the different actors who are involved and possibly directly or indirectly affected by a project or an activity should have full access to the information related to its positive and negative social-environmental impact so that they can inform the relevant public agencies of their opinion. (THOMÉ; RIBEIRO, 2016, p. 76) ${ }^{4}$

Logo, se uma questão que compromete a segurança do meio ambiente de trabalho de um órgão público, com seus servidores estatutários, ela não afeta apenas a eles, mas também a outros como terceirizados que laboram naquele contexto.

\footnotetext{
${ }^{4}$ Tradução: O objetivo nuclear da participação pública é assegurar o exercício da cidadania e da democracia no processo de avaliação de impacto ambiental, momento em que os diversos atores envolvidos e potencialmente afetados, direta ou indiretamente, por projeto ou atividade, devem ter amplo acesso às informações relacionadas ao seu impacto socioambiental, tanto positivos quanto negativos, para que possam externar sua opinião aos órgãos públicos competentes.
} 
Existe uma discussão sobre a inserção do meio ambiente do trabalho, como meio ambiente artificial, sendo que para elucidar de forma mais profunda, sua conceituação e inserção no direito ambiental, será abordado o conceito de vários doutrinadores.

Para José Afonso da Silva, o instituto está inserido no meio ambiente artificial, ou seja, aquele modificado pelo homem, como por exemplo, através de tecnologias:

\begin{abstract}
Merece referência em separado o meio ambiente do trabalho, como o local em que se desenrola boa parte da vida do trabalhador, cuja qualidade de vida está, por isso, em íntima dependência da qualidade daquele ambiente. É um meio ambiente que se insere no artificial, mas digno de tratamento especial, tanto que a Constituição o menciona explicitamente no art. 200, VIII, ao estabelecer que uma das atribuições do Sistema Único de Saúde consiste em colaborar na proteção do ambiente, nele compreendido o do trabalho. $\mathrm{O}$ ambiente do trabalho é protegido por uma série de normas constitucionais e legais destinadas a garantir-lhe condições de salubridade e de segurança. (SILVA, 2013, p. 23-24)
\end{abstract}

Já Para Mônica Maria Lauzid de Moraes, a definição não perpassa necessariamente por incluir o instituto no meio ambiente artificial:

[...] a interação do local de trabalho, ou onde quer que o empregado esteja em função da atividade e/ou à disposição do empregador, com todos os elementos físicos, químicos e biológicos nele presentes, incluindo toda a infra-estrutura (instrumentos de trabalho), bem como o complexo de relações humanas na empresa e todo o processo produtivo que caracteriza a atividade econômica de fins lucrativos. (MORAES, 2002, p. 27)

Nesse contexto, compreendendo a expansão do conceito de meio ambiente do trabalho, como todo o cenário em que o trabalhador foi ou é inserido, em razão de seu labor, importante distinguir meio ambiente do trabalho de direito do trabalho propriamente dito, e assim ensina Celso Antônio Pacheco Fiorillo:

Importante verificar que a proteção do direito do trabalho é distinta da assegurada ao meio ambiente do trabalho, porquanto esta última busca salvaguardar a saúde e a segurança do trabalhador no ambiente onde desenvolve suas atividades. $\mathrm{O}$ direito do trabalho, por sua vez, é o conjunto de normas jurídicas que disciplina as relações entre empregado e empregador. (FIORILLO, 2010, p. 80)

Dessa forma, fica evidenciado que ao se falar de meio ambiente do trabalho, deve-se aplicar tutela diferenciada por envolver direito ambiental, e mesmo considerando a tutela 
trabalhista em si, como bastante eficiente, não se pode esquecer do dever transgeracional incutido no direito ambiental, de garantir o meio ambiente equilibrado para gerações futuras. Sendo deste modo, realmente necessário uma abordagem especial, com interpretações coerentes com a tutela ambiental.

Em harmonia com tal raciocínio, em outra obra, o próprio Celso Antônio Pacheco Fiorillo, explica a base legal para tal abordagem especial ao meio ambiente do trabalho, analisando a Constituição, precisamente em seu artigo $5^{\circ}$ inciso $\mathrm{XXXV}$, pelo direito de prestação jurisdicional, diante até mesmo de uma ameaça de lesão, e ainda o caráter mediato do artigo 225, e o caráter imediato, dos artigos 200 inciso VIII e $7^{\circ}$ inciso XII:

\begin{abstract}
$\mathrm{O}$ direito de agir, garantido pelo artigo $5^{\circ}, \mathrm{XXXV}$, resguarda a possibilidade de submeter à apreciação do Poder Judiciário toda e qualquer lesão ou ameaça ao meio ambiente do trabalho disciplinado juridicamente em nosso país.

$\mathrm{O}$ meio ambiente do trabalho tem proteção ambiental constitucional indicada em decorrência do que determinam mediatamente o art.225 e imediatamente os arts. 200, VIII, e $7^{\circ}$, XXII, da Carta Magna, devendo-se observar o enfoque fundamentalmente preventivo em face da proteção da saúde da pessoa humana resguardada pelo art. 200, VIII, da Constituição Federal - sem todavia deixar de apontar a possibilidade de tutela jurisdicional judicial de referido direito em face de lesão que tenha ocorrido à incolumidade físico-psíquica da pessoa humana. (FIORILLO, 2010, p. 80)
\end{abstract}

Para acionar o judiciário, apoiado na base legal indicada por Fiorillo, a Constituição estabelece dois mecanismos de ação, a ação popular ambiental e ação civil pública, como indica Helena Carvalho Coelho:

Por isso, essa guarda compartilhada do meio ambiente implica um direito e dever do cidadão e do Estado de fiscalizar e de agir em caso de dano ou perigo ao meio ambiente. A importância consagrada na Constituição efetiva o direito à cidadania e evolui no que tange à possibilidade de ações individuais e coletivas, como a Ação Popular Ambiental e a Ação Civil Pública. (COELHO, 2014, p. 63)

Logo, sendo a ação civil pública um instrumento da efetivação do direito ambiental, surge peculiaridades para a chamada ação civil pública ambiental, no intuito de garantir uma efetividade diferenciada, para o direito difuso e coletivo, ao meio ambiente ecologicamente equilibrado, para presentes e futuras gerações.

\title{
3 A AÇÃo CIVIL PÚBLICA AMBIENTAL
}


Nessa forma, como demonstrado no tópico anterior, a ação civil pública ambiental, é um mecanismo processual para efetivar pela via judicial, o direito ambiental lesado, ou ameaçado de ser lesado. Contudo, diferentemente da ação popular, um indivíduo isolado, não possui legitimidade para ajuizar uma ação civil pública ambiental, como ensina Marcelo Abelha Rodrigues:

A ação civil pública é, sem dúvida, a técnica processual (módulo, provimentos $e$ procedimentos) que mais vantagens oferece à tutela jurisdicional do meio ambiente, não obstante a condução ativa da demanda seja exclusiva de entes coletivos, estando fora do rol de legitimados ativos o indivíduo isoladamente ou em litisconsórcio.(RODRIGUES, 2010, p. 98-99)

A previsão legal da ação civil pública está na Lei 7.347/1985, e recebeu novo contorno com o advento da Constituição Federal de 1988, para ser utilizado em causas envolvendo, o direito ambiental, e por consequência, o meio ambiente do trabalho.

Importante destacar que a tutela diferenciada em matéria de meio ambiente, é a voltada para um direito difuso ou coletivo, ou seja, não se aplica, em regra, para causas de natureza individual. E nesta chamada jurisdição civil coletiva, na qual se aplica a tutela diferenciada ambiental, Fiorillo destaca a aplicação em conjunto da lei de ação civil pública, com o Código de Defesa do Consumidor, sendo a aplicação do Código de Processo Civil, em caráter subsidiário:

A defesa do meio ambiente, em razão da natureza do bem tutelado, que, como sabemos é difuso, e conforme determina o art. 19 da Lei da Ação Civil Pública, receberá tratamento direto e primário das normas procedimentais previstas na jurisdição coletiva (CDC + LACP) e somente de forma secundária (subsidiariamente) deverão ser aplicados o Código de Processo Civil e os demais diplomas. (FIORILLO, 2010, p.145)

Quanto a aplicação do Código de Defesa do Consumidor, Marcelo Abelha Rodrigues destaca a possibilidade de se aproveitar o resultado positivo de uma ação civil pública ambiental, para eventuais ações individuais, que já se iniciarão na fase de liquidação, pela utilização do art. 103,§ $3^{\circ}$ do CDC:

Pelo contrário, pela regra da coisa julgada in utilibus (art. 103, $\S 3^{\circ}$ do CDC), os particulares poderão se aproveitar do resultado da ação coletiva ( difusa ou individual homogênea) para liquidar os danos individualmente sofridos. A regra 
processual vem afirmar que o dano ao meio ambiente e o dano ao indivíduo resultante da lesão ao meio ambiente são figuras afins, ligadas pela mesma origem, porém distintas, sendo diverso seu tratamento processual. (RODRIGUES, 2010, p.227)

Ainda no sentido de demonstrar que as ações coletivas, como a ação civil pública, tem meios facilitadores de proteção ao meio ambiente, Fiorillo destaca a isenção do pagamento de custas, mesmo para grandes Associações na defesa do meio ambiente:

\begin{abstract}
Ainda com relação à preocupação do legislador na busca do pleno e eficaz acesso à justiça, temos a dispensa de quaisquer despesas e até mesmo condenação da associação autora quando se tratar de ações coletivas relativas ao Código de Defesa do Consumidor, conforme dispõe o art. 87 do referido diploma, em consonância com a ideia consoante no art. 18 da Lei de Ação Civil Pública, que diz não haver adiantamento de custas, emolumentos, honorários periciais e quaisquer outras despesas, nem condenação da associação autora, ressalvada a comprovação de máfé, em honorários de advogado, custas e despesas processuais, nas ações coletivas de que trata essa lei. (FIORILLO, 2010, p.147)
\end{abstract}

Pela aplicação do Código de Defesa do Consumidor, na ação civil pública ambiental, no âmbito da jurisdição civil coletiva, o juiz ganha novo enfoque, podendo invocar instrumentos como a inversão do ônus da prova, para tutelar o direito transgeracional em debate. (FIORILLO, 2010)

Ao passo que dessa forma, resta evidenciado que a ação civil pública tem aplicação peculiar em se tratando de meio ambiente, e naturalmente ocorre da mesma forma, para o meio ambiente do trabalho, podendo haver tratamento diferenciado, inclusive de normas de competência, pela natureza do bem jurídico a ser tutelado.

\title{
4 COMPETENCIA DA AÇÃO CIVIL PÚBLICA AMBIENTAL SOBRE MEIO AMBIENTE DO TRABALHO
}

Uma vez compreendido sobre o cabimento da ação civil pública ambiental, em causas de meio ambiente do trabalho, passa-se ao questionamento sobre a competência para julgar tal demanda.

Pela redação dada ao artigo 114 da Constituição Federal, em seu inciso I, pela Emenda Constitucional 45/2004, compete a justiça do trabalho processar e julgar: "as ações oriundas da relação de trabalho, abrangidos os entes de direito público externo e da 
administração pública direta e indireta da União, dos Estados, do Distrito Federal e dos Municípios”. (BRASIL, 1988, s.p.)

Logo, por uma literal interpretação do art. 114 da Constituição é possível concluir que em qualquer ação civil pública ambiental, sobre meio ambiente do trabalho, a Justiça do Trabalho seria a competente. Como expõe Norma Sueli Padilha:

\begin{abstract}
Compete à Justiça do Trabalho processar e julgar as lides relativas a indenizações por danos materiais ou morais decorrentes de infortúnio do trabalho promovidas contra o empregador. E, principalmente, no que se refere aos contornos metaindividuais do direito ao meio ambiente do trabalho, compete, ainda, à Justiça Especializada processar e julgar a ação civil pública, que tenha por objeto danos ou ameaças de danos ao meio ambiente laboral. (PADILHA, 2010, p. 404- negrito no original).
\end{abstract}

Contudo, a Associação dos Juízes Federais do Brasil- AJFE, juntamente com a Associação Nacional dos Magistrados Estaduais- ANAMAGES, ajuizou ação direita de inconstitucionalidade, contra o inciso I do artigo 114, no que se refere as demandas envolvendo servidores estatutários, que não tem vínculo celetista, e logo não deveriam, no entendimento destas Associações, ter seu processo julgado na Justiça do Trabalho.

Tal ADI(Ação Direta de Inconstitucionalidade), é de no 3395, e em 01.02.2005, foi publicada liminar do STF, que proíbe interpretação do inciso I do artigo 114, para concluir ser competente a Justiça do Trabalho, para processar e julgar causas envolvendo servidores estatutários.

Em razão de tal suspensão, vários Tribunais Regionais do Trabalho, passaram a entender que a ação civil pública ambiental, em se tratando de meio ambiente do trabalho, não era de competência da Justiça do Trabalho, quando envolvia servidores estatutários.

Enquanto que a competência para julgar a ação civil pública, sobre meio ambiente do trabalho envolvendo trabalhadores celetistas, não sofre tal discussão, sendo decidido de forma pacífica quanto à competência da Justiça do Trabalho, para essas demandas.

Entretanto, cabe discutir se o tema meio ambiente do trabalho, reconhecido como um direito difuso, incindível, e transgeracional, pode ser dividido entre a proteção de trabalhadores celetistas e servidores estatutários.

\title{
4.1 Competência da ação civil pública ambiental sobre meio ambiente do trabalho para servidores estatutários
}

Revista de Direito do Trabalho e Meio Ambiente do Trabalho | e-ISSN: 2525-9857 | Brasília | v. 3 | n. 1 | p. 94 - 114 | Jan/Jun. 2017. 
Diante da liminar dada na ADI 3395, o então juiz convocado, Afrânio Viana Gonçalves, na qualidade de relator no processo de $n^{\circ}$ 00367.2003.001.14.00-412, votou pela incompetência da Justiça do Trabalho, em ação civil pública envolvendo servidor estatutário:

\begin{abstract}
Ainda que se considere que o acordo homologado trata do meio ambiente de trabalho dos médicos e enfermeiros do Estado de Rondônia, ou seja, que decorre dessa "relação de trabalho", e que se procure dar ao inciso I do art. 114 da Carta Magna a interpretação de que o termo "relação de trabalho" envolve também as relações estatutárias, também essa interpretação é inconstitucional, na medida em que no dia 27-01-05 foi concedida liminar pelo Ministro Nelson Jobim nos autos da Ação Direta de Inconstitucionalidade n. 3.395-6, no Supremo Tribunal Federal, suspendendo "toda e qualquer interpretação dada ao inciso I do art. 114 da CF, na redação dada pela EC/45, que inclua na competência da justiça do trabalho, a ... apreciação ... de causas que ... sejam instauradas entre o Poder Público e seus servidores, a ele vinculados por típica relação de ordem estatutária ou de caráter jurídico-administrativo.”. (RONDÔNIA, 2008, p. 6)
\end{abstract}

Esse posicionamento não é inexpressivo, inclusive no processo acima, porque o voto do relator foi acompanhado à unanimidade, pela $2^{\mathrm{a}}$ Turma do Tribunal Regional do Trabalho da $14^{a}$ Região (Rondônia). Sendo que outros Tribunais adotaram posicionamento semelhante, dando interpretação ampliada, a decisão liminar da ADI- 3395, conforme ementas de dois julgados, do Tribunal Regional do Trabalho, da $23^{\text {a }}$ Região, de Mato Grosso, datados de 2012:

AÇÃO CIVIL PÚBLICA. INCOMPETÊNCIA MATERIAL DA JUSTIÇA DO
TRABALHO. SAÚDE, HIGIENE E SEGURANÇA DO TRABALHO DE
SERVIDORES ES-TATUTÁRIOS E/OU QUE POSSUEM RELAÇÃO
JURÍDICO-ADMINISTRATIVA COM A ADMINISTRAÇÃO PÚBLICA. Não é
da Justiça do Trabalho a competência para processar e julgar ação civil pública
visando impor a órgão público o cumprimento de normas voltadas à preservação do
meio ambiente do trabalho (direito social previsto no artigo $7^{\circ}$, XXII, da CF),
quando presentes interesses próprios de servidores estatutários ou que possuam
relação jurídico-administrativa com a Administração consoante decidido na ADI n.
3.395, do Supremo Tribunal Federal. Desse modo, mantém-se intacta a sentença que
declarou a incompetência material da Justiça do Trabalho para apreciar e julgar a
presente ação com a remessa dos autos à Justiça Comum. Recurso não provido.
(MATO GROSSO, 2012, s.p.)

Destaca-se que as decisões declaravam a incompetência da Justiça do Trabalho, remetendo os autos para a Justiça Comum. Cuja além da conhecida lentidão em comparação com a Justiça do Trabalho, a atribuição de várias competências para um mesmo juiz de direito, faz com que seja impossível a prestação jurisdicional adequada para um direito com 
tantas peculiaridades, quanto no que se refere ao meio ambiente do trabalho. Contudo, muitos Tribunais decidiam o tema com tranquilidade, embasados na ADI- 3395, como se verifica:

\begin{abstract}
CONTRARRAZÕES. FAZENDA PÚBLICA. PRAZO. INTEMPESTIVIDADE. Os privilégios da Fazenda Pública quanto a prazos não se aplicam ao prazo para contrarrazoar, que continua sendo de oito dias, como para os demais jurisdicionados. Apresentadas contrarrazões após o oitavo dia, são elas intempestivas. Contrarrazões não conhecidas. AÇÃO CIVIL PÚBLICA. INCOMPETÊNCIA MATERIAL DA JUSTIÇA DO TRABALHO. SAÚDE, HIGIENE E SEGURANÇA DO TRABALHO DE SERVIDORES ESTATUTÁRIOS COM A ADMINISTRAÇÃO PÚBLICA. Não é da Justiça do Trabalho a competência para processar e julgar ação civil pública visando impor a órgão público o cumprimento de normas voltadas à preservação do meio ambiente do trabalho (direito social previsto no artigo $7^{\circ}$, XXII, da $\mathrm{CF}$ ), quando presentes interesses próprios de servidores estatutários ou que possuam relação jurídico-administrativa com a Administração consoante decidido na ADI n. 3.395, do Supremo Tribunal Federal. Desse modo, mantém-se intacta a sentença que declarou a incompetência material da Justiça do Trabalho para apreciar e julgar a presente ação com a remessa dos autos à Justiça Comum. Recurso não provido. (MATO GROSSO, 2012, s.p.)
\end{abstract}

As interpretações acima, da liminar na ADI 3395, podem ser consideradas ampliadas, porque a decisão não falava expressamente sobre o instituto da ação civil pública, tão pouco versava sobre direito ambiental, ou propriamente ao meio ambiente do trabalho.

Nesse compasso, outras decisões surgiram em Tribunais Regionais do Trabalho, decidindo que a liminar da ADI 3395, não se aplica em ação civil pública, especialmente versando sobre meio ambiente do trabalho.

No Tribunal Regional do Trabalho da $1^{\text {a }}$ Região, Rio de Janeiro, em 2013, o desembargador Flávio Ernesto Rodrigues Silva, em relatoria no processo de $\mathrm{n}^{\mathrm{o}}$ : 0031100 93.2009.5.01.0069, assim dispôs em seu voto, sendo acompanhado a unanimidade, pelos julgadores da $10^{\mathrm{a}}$ Turma:

No mais, o Pleno do Supremo Tribunal Federal, no julgamento da ADIn-MC n ${ }^{\circ}$ 3.395, sedimentou o entendimento de que a Justiça do Trabalho é incompetente para examinar causas que versem sobre vínculo de natureza jurídico administrativa e ainda reconheceu, no julgamento do RE $n^{\circ}$ 573202-9, a repercussão geral da referida matéria constitucional, o que levou ao cancelamento da Orientação Jurisprudencial $n^{\circ} 205$ da SBDI-1, do TST. Todavia, a hipótese tratada na ADIn é distinta da que ora se examina. Nos presentes autos, não se discute o vínculo de natureza jurídicoadministrativa entre os servidores e o ente público. A presente ação civil pública tem por foco exigir o cumprimento, pelo Poder Público, de normas trabalhistas relativas à segurança, higiene e saúde dos trabalhadores do Hospital Carlos Chagas. Não se configura, portanto, o descumprimento da decisão liminar proferida nos autos da ADIn 3.395-MC. (RIO DE JANEIRO, 2013, p. 5) 
Nesse julgamento, o Desembargador Flavio Ernesto Rodrigues Silva, não chegou a dar nomenclatura específica de direito ambiental do trabalho, mas ainda assim afastou a aplicação da liminar na ADI 3395, por entender que a causa versava sobre outra hipótese, da que foi base para a liminar. Sendo que a decisão no caso julgado, se referia ao cumprimento de normas de segurança higiene e saúde no trabalho, ou seja, inequivocamente trata-se de meio ambiente do trabalho, como já conceituado nos tópicos iniciais do presente artigo.

Além da perspectiva de se concluir que a ADI não se refere expressamente a ação civil pública, o próprio STF possui um entendimento sumular, que em sua interpretação literal autorizaria a competência da justiça do trabalho, em caso tratando de meio ambiente do trabalho, trata-se da súmula 736 do STF.

No acórdão que representa o referencial teórico do presente artigo, publicado pelo Tribunal Superior do Trabalho, nos autos de $\mathrm{n}^{\mathrm{o}}$ : 128500-70.2013.5.13.0025, o Ministro Relator Hugo Carlos Schermann, também se fundamentou no referido enunciado sumular, como se verifica em trecho do seu voto, que foi acompanhado a unanimidade:

\begin{abstract}
Dessarte, não há como conferir outra solução à lide, que não a de considerar a Justiça do Trabalho competente para as ações alusivas ao meio ambiente do trabalho.Esta é, aliás, a orientação que se extrai da Súmula 736 do STF, cujo teor transcrevo: "COMPETE À JUSTIÇA DO TRABALHO JULGAR AS AÇÕES QUE TENHAM COMO CAUSA DE PEDIR O DESCUMPRIMENTO DE NORMAS TRABALHISTAS RELATIVAS À SEGURANÇA, HIGIENE E SAÚDE DOS TRABALHADORES.". (BRASIL, 2015, p.6)
\end{abstract}

Porém é importante ressaltar que esse entendimento não se sustenta isoladamente, pois o enunciado sumular 736 do STF foi publicado em 2001, antes do advento da Emenda Constitucional 45/2004, que alterou a redação do inciso I do art. 114 da Constituição, e deu origem a ADI 3395, conforme aponta o então juiz convocado, Afrânio Viana Gonçalves, na qualidade de relator no processo de $\mathrm{n}^{\circ}$ 00367.2003.001.14.00-412:

Em relação à Súmula n. 736 do STF, não se aplica ao caso, porque foi publicada em 9-12-2003, não tendo o condão de prevalecer em face da aludida liminar, primeiro porque foi editada antes da EC 45/2004, ou seja, para regular situações decorrentes de relações de emprego, e segundo por não ter efeito vinculante. (RONDÔNIA, 2008, p.7)

Mas como já dito acima, pelos ensinamentos de Fiorillo, um caso que envolve meio ambiente do trabalho, não deve ser tratado apenas com a tutela do direito do trabalho, mas também com a tutela do direito ambiental. (FIORILLO, 2008) 
Nesse sentido, o acórdão objeto do presente artigo, publicado pelo Tribunal Superior do Trabalho, nos autos de $\mathrm{n}^{\mathrm{o}}$ : 128500-70.2013.5.13.0025, contém uma relevante superação hermenêutica, ao tratar o tema com o enfoque ambiental.

O Ministro Relator Hugo Carlos Scheuermann, afastou o argumento sobre a liminar da ADI 3395, não apenas com argumentos legislativos jus laborais, ou com interpretação restritiva da liminar, mas sim com uma interpretação coerente com a tutela ambiental preconizada pelo texto Constitucional.

O tema direito ambiental do trabalhado foi enfrentado formalmente, expondo um alcance peculiar, por tutelar um bem jurídico diferenciado, qual seja, o meio ambiente e em especial o meio ambiente do trabalho:

Com efeito, não há justificativa jurídica ou faticamente plausível para cindir o meio ambiente em setores - celetista e estatutário. O ambiente de trabalho é um só e as diretrizes elementares e imperativas de segurança, saúde e higiene do trabalho aplicam-se a todos os trabalhadores que laboram no recinto público, não guardando relevância a qualificação do vínculo jurídico que possuam com o ente público tomador dos serviços. O que se tutela na presente demanda é a higidez do local de trabalho e não o indivíduo trabalhador em si - e esta é a razão pela qual a qualificação ao vínculo jurídico que ostenta é irrelevante. Dessarte, não há como conferir outra solução à lide, que não a de considerar a Justiça do Trabalho competente para as ações alusivas ao meio ambiente do trabalho. (BRASIL, 2015, p. 6)

E ainda ressaltou um precedente do próprio STF, ao decidir em reclamação constitucional, que a justiça do trabalho é competente para processar e julgar ações envolvendo segurança, saúde e higiene nas condições de trabalho, contra o Poder Público, mesmo sem aprofundar a discussão sob a ótica do meio ambiente do trabalho, como no julgado em análise. O precedente assim expõe:

Tal diretriz foi adotada pela Suprema Corte no julgamento da Reclamação 3.303-PI. Referida decisão teve origem em julgamento de Ação Civil Pública proposta, também pelo Ministério Público do Trabalho, contra o Estado do Piauí, com a finalidade de impor o cumprimento de normas de higiene, saúde e segurança do trabalho no âmbito do IML local. Veja-se:

CONSTITUCIONAL. RECLAMAÇÃO. ADI 3.395-MC. AÇÃO CIVIL PÚBLICA PROPOSTA NA JUSTIÇA DO TRABALHO, PARA IMPOR AO PODER PÚBLICO PIAUIENSE A OBSERVÂNCIA DAS NORMAS DE SAÚDE, HIGIENE E SEGURANÇA DO TRABALHO NO ÂMBITO DO INSTITUTO MÉDICO LEGAL. IMPROCEDÊNCIA. 1. Alegação de desrespeito ao decidido na ADI 3.395-MC não verificada, porquanto a ação civil pública em foco tem por objeto exigir o cumprimento, pelo Poder Público piauiense, das normas trabalhistas 
relativas à higiene, segurança e saúde dos trabalhadores. 2. Reclamação improcedente. Prejudicado o agravo regimental interposto. (BRASIL, 2015, p.6)

Em demonstração de posicionamento consoante com a atual jurisprudência, o relator ainda aponta os seguintes precedentes, do próprio TST, já trabalhando a argumentação justificada pela diferenciada tutela ambiental, do meio ambiente do trabalho: RR - 1023694.2013.5.12.0034, Relator Ministro: Mauricio Godinho Delgado, $3^{\mathrm{a}}$ Turma, DEJT 24/04/2015; e AIRR: 231-85.2011.5.19.0002, Relator Ministro: Aloysio Corrêa da Veiga, $6^{\mathrm{a}}$ Turma, DEJT 06/06/2014.

Afirma a decisão do TST que mesmo com o entendimento de incompetência da justiça do trabalho, como regra geral, quando se trata de servidores estatutários, se a ação civil pública versar sobre meio ambiente do trabalho, abre-se uma exceção, sendo reconhecida a tutela diferenciada ambiental. Desta forma o TST confere um marco ao avanço da efetivação da busca pelo meio ambiente do trabalho sadio. De modo que realmente não é possível conceber uma cisão do meio ambiente do trabalho, para celetistas e estatutários, pois o bem que se tutela é universal, e interligado.

Posto que em direito ambiental, conforme inteligência e comando taxativo do artigo 225 da Constituição, o direito é transgeracional, devendo o magistrado, no caso prático, para conseguir aplicar tal comando, pensar não apenas no direito positivo puro e simples, mas como uma determinada decisão, envolvendo direito ambiental, pode repercutir no futuro. Neste sentido Dempsey Ramos, assim dispõe:

\footnotetext{
Este juiz deve ser antes de tudo um cidadão livre, e não um escravo da lei como postulavam os juristas de Napoleão. Quer dizer, não deve ser um escravo do projeto monoteísta que só conhece uma solução única para os problemas plurais da sociedade complexa e contemporânea. O juiz intergeracional é alguém capaz de abrir a própria mente e reconstruir a racionalidade do conhecimento jurídico que adquiriu nos tempos de sua formação universitária. (RAMOS, 2014, p. 307)
}

Por essa visão sistêmica, global e complexa do direito ambiental, como apontado no acórdão, não é possível dividir o meio ambiente do trabalho, em celetista e estatutário. Neste sentido Elcio Nacur Rezende com Beatriz Souza Costa, ao abordarem sobre uma definição para bem ambiental concluíram: 
A verdade sobre a defesa do meio ambiente, e que deve ser dita, é que não se pode ter tudo. Não há como proteger os bens ambientais separadamente: macrobem/microbem. Meio ambiente tem caráter global, é totalmente complexo. Exemplo disso é o ar que se respira, ou seja, é um só, é biosfera. Existe na propriedade privada o direito documentado a ele? Não, porque é difuso, é de todosnão há aqui pessoas mais favorecidas e menos favorecidas, ou mesmo proprietárias do ar. (COSTA; REZENDE, 2011, p. 67)

Em corroboração com a concepção de um meio ambiente único a ser tutelado, Papa Francisco reforça o caráter indivisível do meio ambiente, em razão de sua complexidade e interligação, defendendo inclusive uma defesa global ao mesmo, a fim de que não seja apenas pelo interesse de alguns, mas sim em prol de toda a humanidade. (FRANCISCO, 2015)

\section{DOS METÓDOS DE APLICABILIDADE DOS PRINCÍPIOS}

Antes de adentrar no próximo tópico abordado no acórdão, sobre como se superar o argumento de violação ao Princípio da Separação de Poderes, para autorizar o Judiciário impor a outros Poderes, o dever de fazer ou não fazer, em prol do meio ambiente do trabalho, é mister compreender duas teorias sobre aplicabilidade de Princípios.

A primeira delas, da qual este artigo não coaduna, mas merece ser explanada, ainda que resumidamente, por ser muito adotada no ordenamento jurídico, é a teoria da Ponderação de Princípios de Robert Alexy. Segundo esta teoria em determinadas situações os Princípios se colidem, devendo ser aplicado o sopesamento dos Princípios para decidir qual deve ser utilizado no caso concreto. (COSTA, 2016)

Um dos problemas mais graves dessa teoria é que primeiramente ela pressupõe uma hierarquia entre Princípios, e em sua efetiva aplicação recai em um forte poder discricionário para o julgador. Pois como não existe uma lei ou ato normativo explicando qual Princípio teria maior peso, o julgador vai decidir cada caso pelo Princípio que lhe parecer superior, tendo as decisões decorrentes desta teoria, enorme subjetividade.

Sendo que com a hermenêutica, seria possível que um julgador definisse por meios escusos, qual decisão tomar, e depois justificasse formalmente, em seu ponto de vista, sobre o peso de determinado Princípio no ordenamento jurídico. Neste sentido, Helena Carvalho Coelho aponta:

[...] Tal teoria é passível de criticas primeiro porque não há uma resolutividade prática apresentada ao problema concreto: a discriscionáriedade, em verdade, é apenas transferida de momento e justificada pelo procedimento de ponderação, que também são escolhas de métodos. (COELHO, 2014, p. 67) 
Outra Teoria, da qual este artigo compactua, é a teoria de Ronald Dworkin, que trabalha com a inexistência de hierarquia entre Princípios, mas sim a percepção que estes coexistem, devendo ser interpretados de forma harmônica, em coerência, e não entendidos como um fim em si mesmos, ou como dogmas ilimitado, pois encontram limites nos demais Princípios, para se manterem coerentes, no ordenamento jurídico ao qual fazem parte.

Humberto Ávila define o critério de Dworkin, para análise de aplicabilidade de Princípios aparentemente divergentes, com a expressão conjugados, no sentido de serem coerentes entre si:

\footnotetext{
Para ele as regras são aplicadas ao modo tudo ou nada (all-or-nothing), no sentido de que, se a hipótese de incidência de uma regra é preenchida, ou é a regra válida e a consequiência normativa deve ser aceita, ou ela não é considerada válida. No caso de colisão entre regras, uma delas deve ser considerada inválida. Os princípios, ao contrário, não determinam absolutamente a decisão, mais somente contém fundamentos, os quais devem ser conjugados, com outros princípios. (ÁVILA, 2009, p. 36-37)
}

Em outras palavras, Dworkin trabalha com uma dosagem na coerência entre os Princípios, pressupondo sua coexistência, e não uma dimensão de 'peso'. (COSTA, 2016). Logo, para análises sobre o meio ambiente do trabalho, deve ser considerado o Princípio da Separação dos Poderes, mas sendo considerado como necessariamente coexistente, com o Princípio da Proteção à Saúde do Trabalhador, da Dignidade da Pessoa Humana, e do Dever de Prestação Jurisdicional diante de lesão ou ameaça de lesão, a um direito, no caso, o direito ambiental do trabalho.

\section{DA SUPERAÇÃO DO ARGUMENTO DE SEPARAÇÃO DE PODERES}

Ainda no acórdão referencial teórico do presente artigo, foi analisada a tese de violação ao artigo $2^{\circ}$ da Constituição Federal, no que se refere ao Princípio de Separação dos Poderes, ao argumento de que o Judiciário não pode impor obrigação de fazer a outro ente público.

O acórdão demonstrou analiticamente, como a Constituição Federal, de forma coerente tutela o meio ambiente, e o meio ambiente do trabalho, sem haver colisão com o princípio da separação de poderes. 
Todavia, o fato de um Princípio estar positivado Constitucionalmente, não o torna ilimitado, mas sim mantém o dever de ser coerente com os demais princípios, incluindo outros que estão igualmente tutelados na Constituição, como o ao meio ambiente equilibrado, esculpido no artigo 225 da Constituição.

Tal raciocínio demonstra a adesão do relator, a teoria de Ronald Dworkin, sobre os Princípios, ao não admitir colisão de Princípios como em Alexy, mas sim a pressupor a coexistência harmônica de todos os Princípios Constitucionais, como se percebe em trecho da decisão:

\begin{abstract}
A teor do artigo 225 da Carta Magna "Todos têm direito ao meio ambiente ecologicamente equilibrado, bem de uso comum do povo e essencial à sadia qualidade de vida, impondo-se ao Poder Público e à coletividade o dever de defendê-lo e preservá- lo para as presentes e futuras gerações". Por sua vez, os artigos $7^{\circ}$, XXII, e 196 da CF dispõem que é direito dos trabalhadores a "redução dos riscos inerentes ao trabalho, por normas de saúde, higiene e segurança" e que "A saúde é direito de todos e dever do Estado, garantido mediante políticas sociais e econômicas que visem à redução do risco de doença e de outros agravos e ao acesso universal e igualitário às ações e serviços para sua promoção, proteção e recuperação". E, a teor do art. 129, II, da CF, é função institucional do Ministério Público zelar pelo efetivo respeito aos direitos assegurados na Constituição Federal. Dessas normas conclui-se que, evidenciada a situação precária a que submetidos os servidores do ente público, imperiosa a atuação do Poder Judiciário, no mister de concretizar direitos fundamentais do trabalhador, não havendo falar, nessa hipótese, em ingerência abusiva de um Poder sobre o outro, tampouco em afronta ao princípio da separação dos poderes. (BRASIL, 2015, p. 9-10)
\end{abstract}

Logo, não há que se falar em violação de separação dos poderes, mas sim em reconhecer uma tutela diferenciada para um direito material repleto de peculiaridades como o direito ao meio ambiente laboral sadio, o que deve ser efetivado pelo caminho mais ágil, que in casu, se mostra ser a Justiça do Trabalho.

\title{
7 DO MÉRITO DO CASO CONCRETO
}

Quanto ao mérito da discussão, se a situação violaria ou não as condições de segurança do meio ambiente do trabalho dos obreiros, esse tema não foi conhecido, pelo recorrente não ter se desincumbido de demonstrar violação apta ao conhecimento do recurso de revista neste aspecto, nos termos do artigo 896 da CLT. 
Mas apenas para citar resumidamente, o caso concreto do julgado, trata-se de um pedido de interdição do prédio onde funciona a Procuradoria Geral do Estado da Paraíba, pela precariedade do ambiente laboral, gerando riscos não apenas para os servidores estatutários que lá trabalham, mas para toda a coletividade. Ressaltando que ao não conhecer o mérito, a decisão do Tribunal Regional foi confirmada, pela interdição do edifício.

É importante destacar que não foi uma tutela pleiteada por direitos individuais, mas sim pela segurança de toda a coletividade. Por isso, o respaldo de mérito, para que a discussão sobre meio ambiente do trabalho, no caso concreto, tenha tratamento diferenciado. Em outras palavras, o caso se insere na tutela diferenciada ambiental, por estar no âmbito da jurisdição civil coletiva. (FIORILLO, 2008)

No intuito de não desviar do enfoque do presente artigo, que é sobre a relevância em se atribuir tratamento diferenciado em matéria ambiental, no contexto do direito do trabalho, influindo em regras de competência, não será analisado o mérito do recurso, que sequer foi conhecido pelo acórdão objeto do presente artigo.

\section{CONSIDERAÇÕES FINAIS}

Como visto o conceito de meio ambiente, é de grande amplitude, tendo vários aspectos, como o relativo ao meio ambiente de trabalho sadio, que é um direito de alcance transgeracional, ou seja, direito até mesmo das futuras gerações.

Adentra-se no campo de aplicação prática para efetivação do direito ao meio ambiente do trabalho em condição digna e salubre, foi exposto que existe uma distinção da tutela trabalhista comum, para a tutela em meio ambiente do trabalho, por envolver o direito a um meio ambiente equilibrado, não apenas no presente, mas também para futuras gerações, nos termos do artigo 225 da Constituição.

No que concerne à efetividade, foi estudado o instituto da ação civil pública ambiental, como meio para concretizar o comando Constitucional. Após tais lições, adentrouse ao tema do acórdão, sobre a competência da Justiça do Trabalho, para processar e julgar as causas envolvendo meio ambiente do trabalho, mesmo que se tratando de servidores estatutários. 
Para compreensão da importância do julgamento pelo TST, publicado no dia 18.08.2015, nos autos de $n^{\text {o: }}$ 128500-70.2013.5.13.0025 foi feita uma analise da evolução jurisprudencial trabalhista e do Supremo Tribunal Federal.

Dentre a análise evolutiva foram levados em conta aspectos legislativos, como a nova redação do inciso I do artigo 114 da Constituição, pela emenda 45/2004, o alcance da liminar na ADI 3395, e ainda a validade da súmula 738 do STF, em se tratando de meio ambiente do trabalho.

Salienta-se que o acórdão em estudo realizou um tratamento diferencial ao tema, ao realmente reconhecer que quando se trata de uma discussão sobre meio ambiente do trabalho, deve haver uma interpretação coerente com a tutela ambiental, e a análise global e complexa sobre questões ambientais.

Diante do acórdão objeto do presente acórdão, conclui-se que houve um importante passo para a efetivação do meio ambiente do trabalho digno, ao surgir em meio a crise política e econômica que o Brasil passa, um julgado capaz de superar entendimentos por muitos anos consolidados, priorizando a tutela ambiental, preconizada no texto Constitucional.

Alia-se o fato de o acórdão ser muito bem fundamentado, indicando precedentes similares recentes, e ainda outras decisões que mesmo sem falar expressamente em meio ambiente do trabalho, acabam por lhe conferir uma tutela diferenciada, a qual faz jus.

Portanto, conclui-se que o julgado objeto do presente artigo, consubstancia-se em um importante precedente da Justiça do Trabalho, em reconhecer uma tutela diferenciada, em meio ambiente do trabalho, influindo até mesmo no alcance da competência estipulada no inciso I do artigo 114 em coerência com o mandamento constitucional do caput do artigo 225, ambos da Constituição Federal.

Assim, o julgado responde o problema central da pesquisa, ao reconhecer que a Justiça do Trabalho é competente para julgar demandas sobre meio ambiente do trabalho de servidores estatutários, pela impossibilidade de divisão do meio ambiente do trabalho para celetistas e estatutários, tendo em vista o conceito uno e complexo, de meio ambiente.

\section{REFERENCIAS}

ÁVILA, Humberto. Teoria dos Princípios da definição à aplicação dos princípios jurídicos. São Paulo: Malheiros, 2009. 
BRASIL. Constituição da República Federativa do Brasil, de 05 de outubro de 1988. Diário Oficial da União, Brasília, 05 out. 1988.

BRASIL. Lei $\mathrm{n}^{\mathrm{a}}$ 7.347, de 24 de julho de 1985. Disciplina a ação civil pública de responsabilidade por danos causados ao meio-ambiente, ao consumidor, a bens e direitos de valor artístico, estético, histórico, turístico e paisagístico e dá outras providências. Diário Oficial da União, Brasília, 25 jul. 1985.

BRASIL. Lei nº 6.938 de 31 de agosto de 1981. Dispõe sobre a Política Nacional do Meio Ambiente, seus fins e mecanismos de formulação e aplicação, e dá outras providências.

Diário Oficial da União, Brasília, 02 set. 1981.

BRASIL. Tribunal Superior do Trabalho. Processo: AIRR-128500-70.2013.5.13.0025. Rel. Ministro Hugo Carlos Scheuermann. Diário de Justiça, 18 de ago. de 2015.

COELHO, Helena Carvalho. Do Direito Constitucional ao meio ambiente e desdobramentos principiológicos à hermenêutica (ambiental?). In: Revista Veredas do Direito- Direito Ambiental e Desenvolvimento Sustentável. Belo Horizonte: Arraes Editores, v. 11, n.21, p.53-73, jan./jun. 2014.

COSTA, Beatriz Souza. Meio ambiente como direito à vida: Brasil, Portugal, Espanha. 3 . ed. Rio de Janeiro: Lumen Juris, 2016.

COSTA, Beatriz Souza; REZENDE, Elcio Nacur. O bem sob a ótica do direito ambiental e do direito civil: uma dicotomia irreconciliável?. In: Revista Brasileira de Políticas Públicas. Brasília: Uniceub, V. 1, n. 3, p. 43-70, 2011.

FARIAS, Paulo José Leite. Competência Federativa e Proteção Ambiental. Porto Alegre: Pena, 1999.

FIORILLO, Celso Antônio Pacheco. Curso de direito ambiental brasileiro. São Paulo: Saraiva, 2008.

FIORILlO, Celso Antônio Pacheco. Princípios do Direito Processual Ambiental. São Paulo: Saraiva, 2010.

FRANCISCO, Sumo Pontífice. Laudato Si'- sobre o cuidado da casa comum. São Paulo: Paulus, 2015.

MATO GROSSO. Tribunal Regional do Trabalho da $23^{\mathrm{a}}$ Região. Processo: RO 1218201100823008 MT. Relator: Desembargadora Leila Calvo. Diário de Justiça, 25 de abr. de 2012.

MATO GROSSO. Tribunal Regional do Trabalho da 23ª Região. Processo: RO: 823201107623000 MT. Rel. Desembargador Osmair Couto. Diário de Justiça, 27 de jun. de 2012. 
MORAES, Mônica Maria Lauzid de. Direito à saúde e segurança no meio ambiente do trabalho. São Paulo: LTR, 2002.

PADILHA, Norma Sueli. Fundamentos Constitucionais do Direito Ambiental Brasileiro. Rio de Janeiro: Elsevier, 2010.

RAMOS, Dempsey. O Futuro como fundamento gnoseológico de validade do direito ambiental. In: Revista Veredas do Direito- Direito Ambiental e Desenvolvimento Sustentável. Belo Horizonte: Arraes Editores, v. 11, n.21, p.281-315, jan./jun. 2014.

RIO DE JANEIRO. Tribunal Regional do Trabalho da $1^{\mathrm{a}}$ Região. Processo: RO 311009320095010069. Rel. Flavio Ernesto Rodrigues Silva. Diário de Justiça, 12 de set. de 2013.

RODRIGUES, Marcelo Abelha. Processo Civil Ambiental. São Paulo: Revista dos Tribunais, 2010.

RONDÔNIA. Tribunal Regional do Trabalho da $14^{\text {a }}$ Região. Processo: RO 00367.2003.001.14.00. Rel. Juiz Convocado Afrânio Viana Gonçalves. Diário de Justiça, 26 de fev. de 2008.

SILVA, José Afonso da. Direito Ambiental Constitucional. São Paulo: Malheiros, 2013.

THOMÉ, Romeu; RIBEIRO, José Cláudio Junqueira. Community Participation in the Analysis of the Environmental Impact Assessment as a Democratic Mechanism to Insure Social-Environmental Rights. Veredas do Direito: Direito Ambiental e Desenvolvimento Sustentável, [S.1.], v. 13, n. 25, p. 69-91, mai. 2016. 